\title{
Pharmacotherapy for gestational diabetes mellitus: still insulin, or what about sulfonylureas?
}

\author{
Angelo Maria Patti ${ }^{1}$, Rosaria Vincenza Giglio ${ }^{1}$, Kalliopi Pafili ${ }^{2}$, Manfredi Rizzo $^{1}$, Nikolaos Papanas ${ }^{2}$ \\ ${ }^{1}$ Department of Internal Medicine and Medical Specialties, University of Palermo, Palermo, Italy; ${ }^{2}$ Diabetes Centre, Second Department of Internal \\ Medicine, University Hospital of Alexandroupolis, Democritus University of Thrace, Alexandroupolis, Greece \\ Correspondence to: Prof. Nikolaos Papanas. Diabetes Centre, Second Department of Internal Medicine, G. Kondyli 22c, Alexandroupolis 68100, \\ Greece. Email: papanasnikos@yahoo.gr. \\ Provenance: This is an invited Editorial commissioned by the Section Editor Qi-Nan Wu (Chongqing University Cancer Hospital \& Chongqing \\ Cancer Institute \& Chongqing Cancer Hospital, Chongqing, China). \\ Comment on: Sénat MV, Affres H, Letourneau A, et al. Effect of Glyburide vs Subcutaneous Insulin on Perinatal Complications Among Women With \\ Gestational Diabetes: A Randomized Clinical Trial. JAMA 2018;319:1773-80.
}

Submitted Oct 23, 2018. Accepted for publication Oct 24, 2018.

doi: $10.21037 / \mathrm{atm} .2018 .10 .60$

View this article at: http://dx.doi.org/10.21037/atm.2018.10.60

Risk factors of gestational diabetes mellitus (GDM) include overweight, hormonal changes, previous GDM, a family history of type 2 diabetes mellitus (T2DM), and polycystic ovarian syndrome $(1,2)$. In approximately $90 \%$ of women, metabolic perturbations are transient $(1,2)$. However, some women progress to T2DM post-partum, with ongoing endothelial inflammation, early atherosclerosis, increased coagulation, insulin resistance, central adiposity, metabolic syndrome (MetS), atherogenic dyslipidaemia and cardiovascular (CV) complications (3-7).

During pregnancy, maternal hyperglycaemia must be avoided by all means (8-10). Thus, pharmacotherapy of GDM for tight glycaemic control is needed to reduce foetal adverse outcomes (11-13). Among oral antidiabetic agents, biguanides and sulfonylureas (SUs) have been used in GDM, but they have never gained wide acceptance (13). The most used SU in GDM is glyburide (12), but insulin is the mainstay of treatment $(13,14)$. SUs are more effective for post-prandial hyperglycaemia and their plasma concentrations are approximately 50\% lower in pregnant women than in non-pregnant patients (15). Secondgeneration SUs pass through the placenta, but it is not clear if placental transfer increase risk of foetal hypoglycaemia and macrosomia $(16,17)$.

In this context, the multicentre study by Sénat et al. (18) has compared glyburide with subcutaneous insulin in GDM in terms of perinatal complications. No significant betweengroup differences were found in the rates of macrosomia, hyperbilirubinaemia, admission to the neonatal intensive care unit, or respiratory distress syndrome (18). However, the glyburide group exhibited increased rates of neonatal hypoglycaemia (18). This is in agreement with the latest meta-analysis (19), as well as other recent studies $(20,21)$.

Based on this new study (18), it appears that glyburide is non-inferior to insulin in preventing perinatal complications, should an oral agent be needed. Nevertheless, there are some limitations to consider (18). First, there was no cross-over design, which would have increased the impact of findings. Secondly, this study used a neonatal criterion as the primary outcome, which was different from other works (19-21), rendering comparisons more difficult.

In conclusion, interesting though the new data may be (18), they do not overall encourage preferring SUs over insulin in GDM. Thus, insulin remains the first-line treatment (13). However, given the easiness of using oral agents, additional trials with SUs in GDM are warranted.

\section{Acknowledgements}

None.

\section{Footnote}

Conflicts of Interest: M Rizzo has received grants and/or fees from Amgen, Astra Zeneca, Boehringer-Ingelheim, 
Eli-Lilly, Meda Pharma, Merck, Novo Nordisk, Roche, Servier. N Papanas has been an advisory board member of TrigoCare International, Abbott, AstraZeneca, Elpen, MSD, Novartis, Novo Nordisk, Sanofi-Aventis and Takeda; has participated in sponsored studies by Eli Lilly, MSD, Novo Nordisk, Novartis and Sanofi-Aventis; received honoraria as a speaker for AstraZeneca, Boehringer Ingelheim, Eli Lilly, Elpen, Galenica, MSD, Mylan, Novartis, Novo Nordisk, Pfizer, Sanofi-Aventis, Takeda and Vianex; and attended conferences sponsored by TrigoCare International, AstraZeneca, Boehringer Ingelheim, Eli Lilly, Novartis, Novo Nordisk, Pfizer and Sanofi-Aventis. The other authors have no conflicts of interest to declare.

\section{References}

1. American Diabetes Association. Diagnosis and classification of diabetes mellitus. Diabetes Care 2013;36:S67-74.

2. Ben-Haroush A, Yogev Y, Hod M. Epidemiology of gestational diabetes mellitus and its association with Type 2 diabetes. Diabet Med 2004;21:103-13.

3. Ridker PM. Inflammatory biomarkers and risks of myocardial infarction, stroke, diabetes, and total mortality: implications for longevity. Nutr Rev 2007;65:S253-9.

4. Rizvi AA. Hypertension, obesity, and inflammation: the complex designs of a deadly trio. Metab Syndr Relat Disord 2010;8:287-94.

5. Damm P, Houshmand-Oeregaard A, Kelstrup L, et al. Gestational diabetes mellitus and long-term consequences for mother and offspring: a view from Denmark. Diabetologia 2016;59:1396-9.

6. Ehrenthal DB, Maiden K, Rogers S, et al. Postpartum healthcare after gestational diabetes and hypertension. J Womens Health (Larchmt) 2014;23:760-4.

7. Rizvi AA, Cuadra S, Nikolic D, et al. Gestational diabetes and the metabolic syndrome: can obesity and small, dense low density lipoproteins be key mediators of this association?. Curr Pharm Biotechnol 2014;15:38-46.

8. Reece EA, Leguizamón G, Wiznitzer A. Gestational diabetes: the need for a common ground. Lancet 2009;373:1789-97.

9. Ju H, Rumbold AR, Willson KJ, et al. Borderline gestational diabetes mellitus and pregnancy outcomes. BMC Pregnancy Childbirth 2008;8:31.

10. HAPO Study Cooperative Research Group, Metzger BE, Lowe LP, et al. Hyperglycemia and adverse pregnancy outcomes. N Engl J Med 2008;358:1991-2002.
11. Seaquist ER, Anderson J, Childs B, et al. Hypoglycemia and diabetes: a report of a workgroup of the American Diabetes Association and the Endocrine Society. J Clin Endocrinol Metab 2013;98:1845-59.

12. Langer O, Conway DL, Berkus MD, et al. A comparison of glyburide and insulin in women with gestational diabetes mellitus. N Engl J Med 2000;343:1134-8.

13. Patti AM, Giglio RV, Pafili K, et al. Pharmacotherapy for gestational diabetes. Expert Opin Pharmacother. 2018;19:1407-14.

14. Simmons D, McElduff A, McIntyre HD, et al. Gestational diabetes mellitus: NICE for the US? A comparison of the American Diabetes Association and the American College of Obstetricians and Gynecologists guidelines with the UK National Institute for Health and Clinical Excellence guidelines. Diabetes Care 2010;33:34-7.

15. Caritis SN, Hebert MF. A pharmacologic approach to the use of glyburide in pregnancy. Obstet Gynecol 2013;121:1309-12.

16. Elliott BD, Schenker S, Langer O, et al. Comparative placental transport of oral hypoglycemic agents in humans: a model of human placental drug transfer. Am J Obstet Gynecol 1994;171:653-60.

17. Balsells M, García-Patterson A, Solà I, et al. Glibenclamide, metformin, and insulin for the treatment of gestational diabetes: a systematic review and metaanalysis. BMJ 2015;350:h102.

18. Sénat MV, Affres H, Letourneau A, et al. Effect of Glyburide vs Subcutaneous Insulin on Perinatal Complications Among Women With Gestational Diabetes: A Randomized Clinical Trial. JAMA 2018;319:1773-80.

19. Song R, Chen L, Chen Y, et al. Comparison of glyburide and insulin in the management of gestational diabetes: A meta-analysis. PLoS One 2017;12:e182488.

20. Bertini AM, Silva JC, Taborda W, et al. Perinatal outcomes and the use of oral hypoglycemic agents. J Perinat Med 2005;33:519-23.

21. Silva JC, Bertini AM, Taborda W, et al. Glibenclamide in the treatment for gestational diabetes mellitus in a compared study to insulin. Arq Bras Endocrinol Metabol 2007;51:541-6.

Cite this article as: Patti AM, Giglio RV, Pafili K, Rizzo M, Papanas N. Pharmacotherapy for gestational diabetes mellitus: still insulin, or what about sulfonylureas? Ann Transl Med 2018;6(Suppl 1):S79. doi: 10.21037/atm.2018.10.60 